Original

\title{
Effect of metal conditioners on polymerization behavior of bonding agents
}

\author{
Takeshi Yoshida ${ }^{1)}$, Kanako Yamaguchi ${ }^{1)}$, Keishi Tsubota ${ }^{2)}$, Toshiki Takamizawa ${ }^{2,3)}$, \\ Hiroyasu Kurokawa ${ }^{2,3}$, Akitomo Rikuta ${ }^{2,3)}$ \\ Susumu Ando ${ }^{2,3)}$ and Masashi Miyazaki ${ }^{2,3)}$ \\ ${ }^{1)}$ Nihon University Graduate School of Dentistry, Tokyo, Japan \\ ${ }^{2)}$ Department of Operative Dentistry, Nihon University School of Dentistry, Tokyo, Japan \\ ${ }^{3)}$ Division of Biomaterials Science, Dental Research Center, \\ Nihon University School of Dentistry, Tokyo, Japan
}

(Received 23 June and accepted 21 September 2005)

\begin{abstract}
This study aimed to determine the influence of metal conditioners on the polymerization behavior of bonding agents. Bonding agents of two-step self-etching primer systems and metal conditioners for adhesion of dental metal alloys were used. Double bond conversion was determined by Fourier transformation infrared spectroscopy. The percentage of residual double bonds, including pendant and monomeric double bonds, was calculated by comparing the obtained ratio with that of the uncured bonding agent. The degree of conversion of the bonding agents was obtained by subtracting the remaining double bonds from $100 \%$. ANOVA followed by a Tukey HDS test was performed. Degree of conversion of the bonding agents ranged from 86.0 to $87.8 \%$. When the bonding agents were mixed with metal conditioners or solvents of the metal conditioners, double bond conversion of the bonding agents tended to decrease. Within the limitations of this study, which was far removed from clinical situations, the presence of metal conditioners and remaining solvents had adverse effects on the polymerization reaction of bonding agents. Clinicians should be cognizant of the various factors that can influence bond strength of restorative resins to dentin. (J. Oral Sci. 47, 171-175, 2005)
\end{abstract}

Correspondence to Dr. Masashi Miyazaki, Nihon University School of Dentistry, Department of Operative Dentistry, 1-8-13 Kanda-Surugadai, Chiyoda-ku, Tokyo 101-8310, Japan

Tel: +81-3-3219-8141

Fax: +81-3-3219-8347

E-mail: miyazaki-m@dent.nihon-u.ac.jp
Keywords: bonding agent; metal conditioner; double bond conversion; solvent.

\section{Introduction}

The two-step self-etching primer system is one of the bonding systems developed to simplify and shorten bonding procedures by combining the dentin conditioning and priming steps $(1,2)$. Self-etching primers are applied to tooth surfaces prior to bonding agent application to ensure maximum adhesion by improving monomer penetration into hydrophilic dentin, and to improve wettability of the tooth surface for the bonding agent. The primed dentin surface is air dried after application of the self-etching primer because the primer contains solvents such as water, ethanol and acetone $(3,4)$. After infiltration of the resin monomers into the partially demineralized dentin, subsequent polymerization of resin monomers is required to create a stable bond. If the polymerization of these monomers is not complete, hydrophilic monomers or small oligomers may be extracted or hydrolyzed by nanoleakage (5).

For minimal intervention dentistry, it is desirable for treatments to include a noninvasive technique and restoration of the affected area, rather than replacement of the fixed prosthesis $(6,7)$. Localized repair with resin composites might be a suitable procedure for increasing the longevity of the restored teeth. Once infected dentin is removed, no further removal of the sound tooth is required if appropriate bonding is used (8). Treatment with alloy and tooth substrate of carious lesions at the crown 
margin requires that both adherend surfaces undergo different surface treatment. In the clinical situation, the question arises as to whether contamination of the tooth substrate by the metal conditioner, including adhesive monomers and solvents, influences the dentin bond strength of resin composites. In a previous study examining the influence of metal conditioner application on bond strength of self-etching primer systems (9), dentin bond strength tended to decrease with metal conditioner application compared to controls without metal conditioner application. One of the reasons for this reduction in bond strength might be changes in the $\mathrm{pH}$ value and molecular conformation of the self-etching primers due to the presence of the metal conditioners. Another explanation for decreasing bond strength might be related to the reduction in mechanical properties of cured bonding agents by the presence of solvents like acetone and ethanol, but further research is required. The purpose of this study was thus to determine the influence of metal conditioner addition on polymerization behavior of bonding agents.

\section{Materials and Methods}

Bonding agents of the self-etching primer systems Clearfil Mega Bond (CB; Kuraray Medical, Tokyo, Japan), Imperva Fluoro Bond (FB; Shofu, Kyoto, Japan), Mac Bond II (MB; Tokuyama Dental, Tokyo, Japan) and UniFil Bond (UB; GC, Tokyo, Japan) were used, as shown in Table 1. A visible light curing unit, Optilux 501 (sds Kerr, Danbury, CT, USA), with a light intensity above $600 \mathrm{~mW} / \mathrm{cm}^{2}$ as measured with a dental radiometer (Model 100, sds Kerr) was used.

Four commercially available metal conditioners were chosen; Alloy Primer (Kuraray Medical), Metal Primer II (GC), Metaltite (Tokuyama Dental) and ML Primer (Shofu), as shown in Table 2 . The main components of the metal conditioners are also listed in Table 2. To determine the influence of solvent addition on polymerization behavior, acetone (EWP0126, Wako Pure Chemical Industries,

Table 1 Bonding agents tested

\begin{tabular}{llll}
\hline $\begin{array}{l}\text { Bonding system } \\
\text { (Code) }\end{array}$ & $\begin{array}{c}\text { Bonding agent } \\
\text { Main components }\end{array}$ & Lot No. & Manufacturer \\
\hline $\begin{array}{l}\text { Clearfil Mega Bond } \\
\text { (CB) }\end{array}$ & $\begin{array}{c}\text { Bond } \\
\text { MDP, HEMA, PI, } \\
\text { bis-GMA, micro filler }\end{array}$ & $00265 \mathrm{~A}$ & $\begin{array}{l}\text { Kuraray Medical, } \\
\text { Tokyo, Japan }\end{array}$ \\
$\begin{array}{l}\text { Imperva Fluoro Bond } \\
\text { (FB) }\end{array}$ & $\begin{array}{c}\text { FB Bond } \\
\text { 4-MET, HEMA, filler, } \\
\text { UDMA, TEGDMA, PI }\end{array}$ & 109963 & $\begin{array}{l}\text { Shofu, } \\
\text { Kyoto, Japan }\end{array}$ \\
$\begin{array}{l}\text { Mac Bond II } \\
\text { (MB) }\end{array}$ & $\begin{array}{c}\text { Bonding agent } \\
\text { MAC-10, HEMA, PI, } \\
\text { bis-GMA, TEGDMA }\end{array}$ & 0248 & $\begin{array}{l}\text { Tokuyama Dental, } \\
\text { Tokyo, Japan }\end{array}$ \\
$\begin{array}{l}\text { UniFil Bond } \\
\text { (UB) }\end{array}$ & $\begin{array}{l}\text { Bonding agent } \\
\text { TEGDMA, HEMA, }\end{array}$ & \\
\hline & UDMA, PI & 0302281 & GC, \\
\hline
\end{tabular}

Tokyo, Japan), ethanol (EWM2559, Wako Pure Chemical Industries) and methyl methacrylate (DLQ1742, Wako Pure Chemical Industries) were used.

Double bond conversion of the bonding agents was determined by Fourier transformation infrared spectroscopy (FTIR; 480 Plus, JASCO, Tokyo, Japan). Bonding agents were mixed with each metal conditioner or solvent at a ratio of 10:1. Mixed solutions or bonding agents (control) were placed in a Teflon ${ }^{\circledR}$ mold $(4 \mathrm{~mm}$ in diameter $\times 1 \mathrm{~mm}$ in height), the surface was covered with a cover glass and then exposed to light for $60 \mathrm{~s}$. Cured specimens were pulverized into a fine powder, mixed with potassium bromide powder and compacted to form a specimen for IR spectroscopy. IR spectra were obtained from 30 scans over the 400 $4000 \mathrm{~cm}^{-1}$ range at a resolution of $2 \mathrm{~cm}^{-1}$.

Measurement of residual double bonds was made on a relative basis by comparing the $\mathrm{C}=\mathrm{C}$ unpolymerized methacrylate stretching vibration $\left(1637 \mathrm{~cm}^{-1}\right)$ to that of the $\mathrm{C}=\mathrm{O}$ stretching vibration of the aromatic ring $\left(1608 \mathrm{~cm}^{-1}\right)$ for bonding agents containing Bis-GMA or to the $\mathrm{C}-\mathrm{H}$ stretching vibration of the aliphatic group $\left(2960 \mathrm{~cm}^{-1}\right)$ for bonding agents containing UDMA. The $\mathrm{C}=\mathrm{O}$ stretching mode at $1608 \mathrm{~cm}^{-1}$ and $\mathrm{C}-\mathrm{H}$ stretching vibration at 2960 $\mathrm{cm}^{-1}$ were used as internal standards for Bis-GMA-based and UDMA-based bonding agents, respectively.

The intensities of individual bands were obtained from the peak areas by curve fitting software (Spectra manager, JASCO), which was designed to calculate a Lorentzian curve. In this way, the ratios of the two band areas were calculated at each measuring point and the percentage of double bond conversion was calculated by subtracting the percentage of remaining double bonds from $100 \%$. It should be noted that the obtained percentages were based on the assumption of linearity in the ratios between uncured and cured states, and on the assumption that unreacted pendant methacrylate groups bound to the polymer network are not available for leaching as residual monomer. Five specimens for each combination were measured.

Table 2 Metal conditioners used

\begin{tabular}{|c|c|c|c|}
\hline Cinditioner & Lot No. & Main component & Manufacturer \\
\hline ML Primer & MTLO01 & $\begin{array}{l}\text { 10-methacryroxydecyl-6,8-dithiooctanate } \\
\text { (10-MDDT), 6-methacryloxyhexyl } \\
\text { phosphonoacetate (6-MHPA), acetone }\end{array}$ & $\begin{array}{l}\text { Shofu Inc., } \\
\text { Kyoto, Japan }\end{array}$ \\
\hline Alloy Primer & $0138 \mathrm{AA}$ & $\begin{array}{l}\text { 6-(4-vinylbenzyl-n-propyl)amino- } \\
\text { 1,3,5-triazine-2,4-dithiol (VTD), } \\
\text { 10-methacryloyl-oxydecyl } \\
\text { dihydrogen phosphatc (MDP), acetone }\end{array}$ & $\begin{array}{l}\text { Kuraray Mcdical } \\
\text { Tokyo, Japan }\end{array}$ \\
\hline Metaltite & 00403 & $\begin{array}{l}\text { 6-methacryloyloxyhexyl-2-thiouracil- } \\
\text { 5-carboxylate (MTU-6), ethanol }\end{array}$ & $\begin{array}{l}\text { Tokuyama Dental } \\
\text { Tokyo, Japan }\end{array}$ \\
\hline Metal Primer II & 013072 & $\begin{array}{l}\text { Methacryloyloxyalkyl thiophosphate } \\
\text { derivatives (MEPS), } \\
\text { methyl methacrylate (MMA) }\end{array}$ & $\begin{array}{l}\text { GC Corp. } \\
\text { Tokyo, Japan }\end{array}$ \\
\hline
\end{tabular}


Results were analyzed by calculating the mean and standard deviation for each group. Data for each specimen were subjected to ANOVA followed by Tukey HSD test at a significance level of 0.05 . Statistical analysis was carried out using the Sigma Stat ${ }^{\circledR}$ software system (SPSS, Chicago, IL, USA).

\section{Results}

The results for double bond conversion with various combinations of metal conditioners and bonding agents are shown in Table 3. After $24 \mathrm{~h}$ storage in water, the DC of the bonding agents was $86.8 \%$ for $\mathrm{CB}, 86.2$ for $\mathrm{FB}$, $86.0 \%$ for $\mathrm{MB}$ and $87.8 \%$ for UB. When the metal conditioners were mixed with bonding agents, the double bond conversions of the bonding agents tended to decrease. With the metal conditioners, double bond conversion varied, ranging from 72.2 to $82.5 \%$ for $\mathrm{CB}$, from 61.3 to $73.2 \%$ for $\mathrm{FB}$, from 65.6 to $72.8 \%$ for $\mathrm{MB}$ and from 64.2 to $67.5 \%$ for UB.

The results for double bond conversion with various combinations of solvents and bonding agents are shown in Table 4. When the solvents were mixed with bonding agents, double bond conversion of the bonding agents tended to decrease. With the metal conditioners, double bond conversion varied, ranging from 78.1 to $80.8 \%$ for $\mathrm{CB}$, from 73.8 to $82.0 \%$ for $\mathrm{FB}$, from 76.9 to $81.3 \%$ for $\mathrm{MB}$ and from 74.5 to $80.7 \%$ for UB.

\section{Discussion}

To establish an authentic hybrid layer, bonding agent must be supplied to infiltrate the exposed collagen fibril network in the demineralized dentin and followed by polymerization (10). Hypothetically, stronger resins lead to stronger dentin bonding (11). The strength of cured bonding agent is dependent on many factors, such as composition, degree of conversion and length of polymer chain (12). Unreacted resin monomer remaining in bonding agents may alter their mechanical properties. Thus, it is important to evaluate the polymerization characteristics of

Table 3 Influence of metal conditioners on double bond conversion $(\%)$ of bonding agents

\begin{tabular}{lccccc}
\hline \multirow{2}{*}{ Bonding agent } & Control & ML Primer & Alloy Primer & Metaltite & Metal Primer II \\
\hline CB & $86.8(2.1)^{\mathrm{a}}$ & $82.5(3.3)^{\mathrm{a}} \mathrm{b}$ & $85.4(3.1)^{\mathrm{a}}$ & $78.1(2.7)^{\mathrm{b}}$ & $72.2(2.6)^{\mathrm{c}}$ \\
FB & $86.2(2.2)^{\mathrm{d}}$ & $71.2(3.1)^{\mathrm{c}}$ & $69.0(2.3)^{\mathrm{e}}$ & $73.2(3.3)^{\mathrm{c}}$ & $61.3(2.5)^{\mathrm{f}}$ \\
MB & $86.0(2.7)^{\mathrm{g}}$ & $72.8(3.1)^{\mathrm{h}}$ & $72.0(2.8)^{\mathrm{h}}$ & $69.4(2.6)^{\mathrm{h}, \mathrm{i}}$ & $65.6(2.8)^{\mathrm{j}}$ \\
UB & $87.8(2.3)^{\mathrm{j}}$ & $67.5(2.9)^{\mathrm{k}}$ & $71.4(3.0)^{\mathrm{k}}$ & $70.5(2.8)^{\mathrm{k}}$ & $64.2(3.2)^{\mathrm{b}}$ \\
\hline
\end{tabular}

Valucs with the same letter in cach bonding agent are not significantly different $(p>0.05)$. Number of specimens are 5 . bonding agents.

Several approaches are employed to measure conversion in restorative resins; the majority of analytical studies have been performed using FTIR (13-17). Measurement of double bond conversion is based on the measured decrease in intensity of the methacrylate $\mathrm{C}=\mathrm{C}$ stretching mode absorption at $1637 \mathrm{~cm}^{-1}$ as the methacrylate monomer is converted to polymer. These procedures rely on the presence of a stable absorption band that does not change as a consequence of polymerization. In Bis-GMA based resins, the aromatic absorption at $1608 \mathrm{~cm}^{-1}$ served as an internal standard to normalize the monomer and polymer spectra. In UDMA-based resins, the C-H stretching mode absorption at $2960 \mathrm{~cm}^{-1}$ and $\mathrm{C}=\mathrm{O}$ stretching absorption were used as internal standards. The positions of these peaks were not affected by the metal conditioners or solvents used in this study.

The double bond conversion in methacrylate groups depends on resin monomer composition (18) and concentration of polymerization initiators $(19,20)$. Based on the results of this study, the double bond conversion of the bonding agent appears to depend on the metal conditioners mixed with them. Incorporation of metal conditioners interfered with polymerization of the bonding agents and reductions in double bond conversion were observed (Table 3 ).

One of the reasons for decreasing double bond conversion could be the incorporation of solvent from the metal conditioners into the bonding agent (Table 4). This would alter the polymerization of the resin monomers (21). It has been reported that increases in the initial acetone content of bonding agents resulted in lower dentin bond strength (22). It was speculated that higher acetone content in bonding agent leaves residual solvent, which would then lead to inferior mechanical properties. Similar trends may be observed with other solvents, such as ethanol or methyl methacrylate.

Another factor to consider is the polymerization reaction itself. The bonding agents used in this study are cured by

Table 4 Influence of solvent on double bond conversion (\%) of bonding agents

\begin{tabular}{lllll}
\hline Bonding agent & Control & Acetone $^{\text {Solvent }}$ & Ethanol & Methyl methacrylate \\
\hline CB & $86.8(2.1)^{\mathrm{a}}$ & $80.6(2.9)^{\mathrm{b}}$ & $80.8(3.1)^{\mathrm{b}}$ & $78.1(3.0)^{\mathrm{b}}$ \\
FB & $86.2(2.2)^{\mathrm{d}}$ & $82.0(2.6)^{\mathrm{e}}$ & $78.5(2.8)^{\mathrm{e}}$ & $73.8(2.5)^{\mathrm{f}}$ \\
MB & $86.0(2.7)^{\mathrm{g}}$ & $81.3(3.0)^{\mathrm{h}}$ & $77.4(2.7)^{\mathrm{h}, \mathrm{i}}$ & $76.9(2.7)^{\mathrm{i}}$ \\
UB & $87.8(2.3)^{\mathrm{j}}$ & $80.7(3.1)^{\mathrm{k}}$ & $74.5(2.6)^{\mathrm{k}}$ & $76.9(2.8)^{\mathrm{1}}$ \\
\hline
\end{tabular}

Values with the same letter are not significantly different $(P>0.05)$. Number of specimens was 5 . 
free radical polymerization and the photosensitizive initiator camphorquinone (CQ) $(23,24)$. CQ requires a coinitiator for effective polymerization, and a tertiary amine photoreductant is employed. The tertiary amine interacts with the activated triplet state of CQ to form an intermediate excited complex, followed by production of reactive radicals for polymerization (25). The decreased double bond conversion could be related to the functional monomers in the metal conditioners.

A functional monomer of VTD is utilized with MDP monomer in the Alloy Primer. The mercapto groups in VTD react with noble metal alloys at the metal/resin cement interface (26). An NMR study showed that VDT has a thione-type structure, which is considered to be chemically stable, in both the solid state and in acetone solution (27). When VDT molecules come close to the Au surface, tautomerization occurs and chemically active mercapto groups interact with noble metal elements (28). The Metal Primer II contains MEPS, an athiophosphate compound, to react with noble metal alloys (29), while Metaltite contains MTU-6 monomer, which has a thiol structure similar to the thione structure in VDT monomer (29). ML Primer contains a thiooctanate monomer (10-MDDT), which has a disulfide structure for bonding to noble metal alloys, and a phosphonoacetate monomer (6-MHPA) for bonding to base metal alloys.

Thiols have been employed as efficient chain transfer agents because of the weakness of the S-H bond and the higher reactivity of thiol radicals $(29,30)$. Addition polymerization of resin monomers in the bonding agent might be terminated by the presence of thiol radicals, thus leading to decreased polymer chain length. Unreacted resin monomer remaining in bonding agents may alter their polymerization reactions. It has been suggested that the inclusion of reducing agents other than tertiary amines in bonding agents resulted in increased bond strength (31). The bonding agent $\mathrm{CB}$ contains a sulphinic acid salt and this ingredient might act as a scavenger for oxygen to maintain DC, even after mixing with metal conditioner.

Other factors that affect residual double bonds in the bonding agent include elution of monomers into water during the storage period of the specimen (32). The elution rate of components from composite resins is reportedly rapid during the initial period of solvent immersion, leading to substantial solutions. It is possible that the uncured monomers leach during storage in water, thus reducing the amount of uncured remaining double bonds.

Within the limitations of this in vitro study, which was far removed from clinical situations, double bond conversion of bonding agents tended to be deteriorated by the presence of metal conditioners. Further research will determine whether metal conditioner contamination leads to inferior clinical performance of self-etching primer restorative systems.

\section{Acknowledgments}

This work was supported, in part, by a Grant-in-Aid for Scientific Research (C) (2) 17592004 from the Japan Society for the Promotion of Science and by a grant from the Ministry of Education, Culture, Sports, Science, and a grant from Dental Research Center, Nihon Unicersity School of Dentistry.

\section{References}

1. Van Meerbeek B, Perdigão J, Lambrechts P, Vanherle G (1998) The clinical performance of adhesives. J Dent 26, 1-20

2. Perdigão J, Lopes M (1999) Dentin bonding questions for the new millennium. J Adhes Dent 1, 191-209

3. Miyazaki M, Hirohata N, Takagaki K, Onose H, Moore BK (1999) Influence of self-etching primer drying time on enamel bond strength of resin composites. J Dent 27, 203-207

4. Chiba Y, Yamaguchi K, Miyazaki M, Tsubota K, Takamizawa T, Moore BK (2006) Effect of airdrying time of single-application self-etch adhesives on dentin bond strength. Oper Dent 31 (in press)

5. Sano H, Yoshikawa T, Pereira PNR, Kanemura N, Morigami M, Tagami J, Pashley DH (1999) Longterm durability of dentin bonds made with a selfetching primer, in vivo. J Dent Res 78, 906-911

6. Tyas MJ, Anusavice KJ, Frencken JE, Mount GJ (2000) Minimal intervention dentistry - a review. FDI Commission Project 1-97. Int Dent J 50, 1-12

7. Mount GJ, Ngo H (2000) Minimal intervention: a new concept for operative dentistry. Quintessence Int 31, 527-533

8. Peters MC, McLean ME (2001) Minimally invasive operative care. II. Contemporary techniques and materials: an overview. J Adhes Dent 3, 17-31

9. Yoshida T, Miyazaki M, Hirohata N, Moore BK (2005) Influence of metal conditioner contamination of the dentin surface on bond strengths of dentin adhesive systems using self-etching primers. Oper Dent 30, 359-367

10. Miyazaki M, Onose H, Moore BK (2002) Analysis of the dentin-resin interface by use of laser Raman spectroscopy. Dent Mater 18, 576-580

11. Pashley DH, Ciucchi B, Sano H, Carvalho RM, Russell CM (1995) Bond strength versus dentine structure: a modelling approach. Arch Oral Biol 
40, 1109-1118

12. Peutzfeldt A (1997) Resin composites in dentistry: the monomer systems. Eur J Oral Sci 105, 97-116

13. Asmussen E (1982) Factors affecting the quality of remaining double bonds in restorative resin polymers. Scand J Dent Res 90, 490-496

14. Ferracane JL, Greener EH (1984) Fourier transform infrared analysis of degree of polymerization in unfilled resins - methods comparison. J Dent Res 63, 1093-1095

15. Ruyter IE, Øysæd H (1987) Composites for use in posterior teeth: composition and conversion. J Biomed Mater Res 21, 11-23

16. Rueggeberg FA, Hashinger DT, Fairhurst CW (1990) Calibration of FTIR conversion analysis of contemporary dental resin composites. Dent Mater 6, 241-249

17. Yamada M, Miyazaki M, Moore BK (2004) Influence of interchanging adhesive resins and selfetching primers on mechanical properties of the adhesive resins. Oper Dent 29, 532-537

18. Shimomura H (1987) Photochemical studies on composite resins cured by visible light. Dent Mater J 6, 9-27

19. Yoshida K, Greener EH (1994) Effect of photoinitiator on degree of conversion of unfilled lightcured resin. J Dent 22, 296-299

20. Sideridou I, Tserki V, Papanastasiou G (2002) Effect of chemical structure on degree of conversion in light-cured dimethacrylate-based dental resins. Biomaterials 23, 1819-1829

21. Jakubiak J, Rabek JF (1999) Photoinitiators for visible light polymerization. Polimery 44, 447-461

22. Cho BH, Dickens SH (2004) Effects of the acetone content of single solution dentin bonding agents on the adhesive layer thickness and the microtensile bond strength. Dent Mater 20, 107-115

23. Cook WD (1992) Photopolymerization kinetics of dimethacrylates using the camphorquinone/amine initiator system. Polymer 33, 600-609

24. Okaya T, Kikuchi K, Morii Y (1997) Polymerization of acrylamide in aqueous medium initiated with a redox system of cysteine and ammonium persulfate. Polymer J 29, 545-549

25. Henríquez C, Bueno C, Lissi EA, Encinas MV (2003) Thiols as chain transfer agents in free radical polymerization in aqueous solution. Polymer 44, 5559-5561

26. Kojima K, Kadoma Y, Imai Y (1987) Adhesion to precious metals utilizing triazine dithione derivative monomer. Shikazairyokikai 6, 702-707

27. Mizuno A, Toda Y, Itoh M, Kojima K, Kadoma Y (1998) NMR analysis of thione-thiol tautomerization of a triazine derivative in the solid state and in acetone solution. J Mol Struct 441, 149-153

28. Suzuki M, Fujishima A, Miyazaki T, Hisamitsu H, Kojima K, Kadoma Y (1999) A study on the adsorption structure of an adhesive monomer for precious metals by surface-enhanced Raman scattering spectroscopy. Biomaterials 20, 839-845

29. Matsumura H, Shimoe S, Nagano K, Atsuta M (1999) Effect of noble metal conditioners on bonding between prosthetic composite material and silverpalladium-copper-gold alloy. J Prosthet Dent 81, 710714

30. Hotta M, Kondoh K, Kamemizu H (1998) Effect of primers on bonding agent polymerization. J Oral Rehabil 25, 792-799

31. Taira M, Urabe H, Hirose T, Wakasa K, Yamaki M (1988) Analysis of photo-initiators in visible-lightcured dental composite resins. J Dent Res 67, 2428

32. Munksgaard EC, Irie M, Asmussen E (1985) Dentinpolymer bond promoted by Gluma and various resins. J Dent Res 64, 1409-1411

33. Ferracane JL (1994) Elution of leachable components from composites. J Oral Rehabil 21, 441-452 